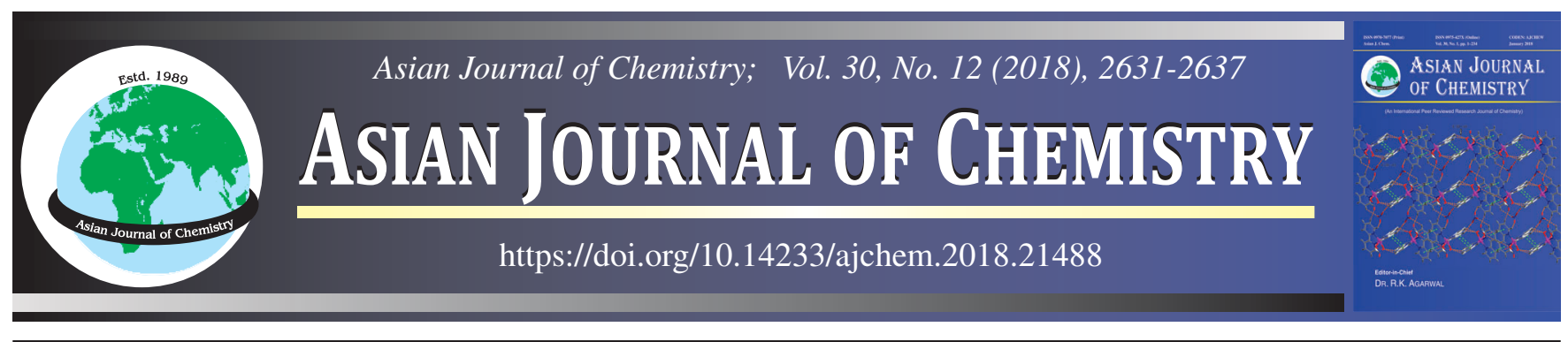

\title{
Synthesis, Structural and Optical Properties of Mn Doped ZnO with its Photocatalytic Activity
}

\author{
P. Gautham ${ }^{1}$, U. Sachin Varma ${ }^{1}$, K.M. SReekanth ${ }^{1, *}$, D.V. Ravi Kumar ${ }^{1}$, K.M. SReedhar ${ }^{2}$ and G. Sivasubramanian ${ }^{1}$
}

${ }^{1}$ Department of Sciences, Amrita School of Engineering, Amrita Vishwa Vidyapeetham, Coimbatore-641 112, India

${ }^{2}$ Department of Chemistry, Amrita School of Arts \& Sciences, Amrita Vishwa Vidyapeetham, Amritapuri-690 525, India

*Corresponding author: E-mail: km_sreekanth@cb.amrita.edu

Received: 29 May 2018;

Accepted: 19 July 2018;

Published online: 31 October 2018;

AJC-19123 Metal oxides have emerged as one of the most interesting materials under the Green banner due to its potent catalytic properties. Especially,
the II-VI metal oxides are gaining considerable attention in optoelectronics and in rectifying environmental issues due to their ability to
produce charge carriers when accelerated with sufficient amount of energy. Zinc oxide and $\mathrm{Mn}_{\mathrm{x}} \mathrm{Zn}_{(1-\mathrm{x})} \mathrm{O}$ were synthesized by co-precipitation
method. We present a study of effect of doping on the structural, optical and photocatalytic properties of $\mathrm{ZnO}$. The mean particle size was
found to decrease from $20 \mathrm{~nm}$ to $11 \mathrm{~nm}$ and band gap $\left(\mathrm{E}_{\mathrm{g}}\right)$ increased from $3.25 \mathrm{eV}$ to $3.68 \mathrm{eV}$ with the increase of doping concentration.
This increase in $\mathrm{E}_{\mathrm{g}}$ might be ascribed to the alteration of electronic arrangement of $\mathrm{ZnO}$ nanoparticles on doping with Mn ions. Photocatalytic
reduction was conducted in a home-built reactor assembly and degradation of $\mathrm{Cr}(\mathrm{VI})$ to $\mathrm{Cr}(\mathrm{III})$ under the presence of $\mathrm{UV} \mathrm{LED}$ was
characterized. In the current work, 15 mol \% of Mn doped $\mathrm{ZnO}\left(\mathrm{Mn}_{0.15} \mathrm{Zn}_{0.85} \mathrm{O}\right)$ nanoparticles showed the better $\mathrm{UV}$ response as compared
to the other samples. The strong UV response is due to the more $3 d$ orbitals in the valence band owing to an excess amount of Mn dopants
in $\mathrm{ZnO}$ nanoparticles. The increase in doping concentration of Mn accelerated the photo catalysis. This result indicates that the concentration
of Mn is important in controlling the UV response of the samples. The obtained results reveal that both $\mathrm{ZnO}_{\text {and } \mathrm{Mn}} \mathrm{Mn} \mathrm{Zn}_{(1-\mathrm{x})} \mathrm{O}$ are
promising materials as photo catalysts.

Keywords: Metal oxide semiconductor, Chromium, Crystallite size, Photocatalytic activity.

ᄂ - - - - - - - - - - - - - - - - - - - - - - - - - - - - - - - - -

\section{INTRODUCTION}

Industrial development is an inevitable factor in the growth of any nation and on the other hand it's also the factor for increasing the pollution caused from hazardous metals [1]. Irrelevant of whether advanced or not, the problem faced by almost all sectors of every country is the rottenness caused mainly by ground water contamination, air pollution in large scale and hazardous metal wastes. Chromium is a metal that has found its place in the industrial area with its wide application in electroplating, tanning, refractory materials, wood preservatives and many more [2] but it has also received biological attention due to its major role in contributing to the industrial pollution and its toxicity to plants and animals [3]. The existence of $\mathrm{Cr}$ is in two states, i.e., trivalent and hexavalent chromium. The hexavalent form of chromium is 500 times more toxic than the trivalent form [4]. Chromium(VI) and its compounds are highly toxic when inhaled or ingested. It is hemotoxic, genotoxic and carcinogenic. When hexavalent chromium enters the bloodstream, it damages blood cells by causing oxidation reactions. This oxidative damage can lead to haemolysis and, ultimately, kidney and liver failure. Patients might be treated with dialysis, whereas trivalent chromium is a trace mineral that is essential to human nutrition. Industrial sources release $\mathrm{Cr}(\mathrm{VI})$ in effluent streams and should immediately be treated before combining with ground water. The removal of $\mathrm{Cr}(\mathrm{VI})$ can be done through various means such as ion exchange [5], adsorption [6] and electrocoagulation [7]. Another alternative for the degradation of $\mathrm{Cr}(\mathrm{VI})$ is photocatalytic reduction with semiconductors like $\mathrm{ZnO}$ under irradiation with UV or visible light [8].

Semiconductor photo catalysis is a newly advanced oxidation process and is suitable for the degradation of pollutants. Zinc oxide is a semiconductor existing in cubic zinc blende, cubic rocksalt and hexagonal wurtzite structure [9]. Wide direct band gap $\left(\mathrm{E}_{\mathrm{g}} \sim 3.7 \mathrm{eV}\right)$ and high exciton binding energy (60 $\mathrm{MeV}$ ) along with the bulk availability as single crystal make $\mathrm{ZnO}$ a good aspirer for optoelectronic devices [10,11] and it

This is an open access journal, and articles are distributed under the terms of the Creative Commons Attribution-NonCommercial 4.0 International (CC BY-NC 4.0) License, which allows others to copy and redistribute the material in any medium or format, remix, transform, and build upon the material, as long as appropriate credit is given and the new creations are licensed under the identical terms. 
has made a great impact in the fields like biosensors [12] and UV light emitters [8]. The pertinence of semiconductors like $\mathrm{TiO}_{2}, \mathrm{ZnO}, \mathrm{Fe}_{2} \mathrm{O}_{3}, \mathrm{CdS}$ and $\mathrm{ZnS}$ is due to the electronic structure of the metal atom in chemical combination, where the electronic structure is constituted by a filled valence band (VB) and an empty conduction band (CB). One of the greatest advantages of $\mathrm{ZnO}$ is that it absorbs a large margin of UV spectrum compared to $\mathrm{TiO}_{2}$ and the corresponding threshold of $\mathrm{ZnO}$ is 425 $\mathrm{nm}$ [13]. Zinc oxide is reported highly stable under high energy radiation [9]. Numerous experimental attempts have been made to alter its properties for wide variety of functionalities. Recently, introduction of band gap engineering [14] into II-VI semiconducting materials has gained much more consideration due to its excellent structural, optical, electrical, photocatalytic and magnetic properties [14-18]. Band gap engineering can alter the electronic band structure in the desired form by changing the composition of semiconductors with doping. Also, tailoring and tuning the $\mathrm{E}_{\mathrm{g}}$ by the introduction of transition metal ions into the cationic metal sites of the host lattice has earned much more consideration in the recent few years. Band gap engineering is a powerful and indispensable tool to be performed for the design of new photocatalytic semiconductor materials and their applications $[19,20]$. This can be done through doping and alloying $\mathrm{ZnO}$ with transition metals. In the course of doping, the ionic radius of dopant should be nearly equal to that of $\mathrm{Zn}$ ion so that the replacement of $\mathrm{Zn}$ ions by dopants does not change the lattice constant of host crystal significantly. The radius of $\mathrm{Mn}^{2+}$ is comparatively [21] close to the radius of $\mathrm{Zn}^{2+}$. Hence, the $\mathrm{Mn}$ is assumed to be a profound donor in $\mathrm{ZnO}$. Many research groups have examined the properties of $\mathrm{ZnO}$ powder and $\mathrm{ZnO}$ doped with selected transition metal ions [19-22]. The preparation method and the ambient conditions affect the characteristic properties of metal oxide semiconductors. Different methods of synthesis such as hydrothermal [22], sol-gel [23], co-precipitation [24], combustion [25], solvo-thermal [26] etc. are used to prepare doped and undoped $\mathrm{ZnO}$. Out of these, co-precipitation synthesis is of low cost and eco-friendly.

Of late, the significant interest in UV/light induced chemical reactions on the transition metal-doped $\mathrm{ZnO}$ in slurry is increasing. The studies are fewer in number and therefore the effect of dopant on $\mathrm{ZnO}$ is still ambiguous [22,27]. A group of researchers reported that the photocatalytic activity, upon irradiation with UV of $\mathrm{Mn}_{\mathrm{X}} \mathrm{Zn}_{(1-\mathrm{X})} \mathrm{O}$ increases up to $\mathrm{x}=2 \mathrm{~mol} \%$. On the other hand, some group have reported inversely [28]. Moreover, it is a simple technology for detoxification of water, eliminating all types of contaminants and in destroying many viruses on the illumination of UV/light under ambient conditions. The establishment of photo catalysis as an effective method for reducing the toxicity of organic compounds and hazardous inorganic constituents and also for the bacteria disinfection of air and water has been progressed in a large scale [29]. The photocatalytic property of $\mathrm{ZnO}$ has been proved dynamic [1]. These photocatalytic semiconductors have $\mathrm{E}_{\mathrm{g}}$ in the UV region. The photocatalytic property will enact after getting illuminated by UV light rays. Natural light is not a dependable source to observe photo catalysis since the solar spectrum contain $46-47 \%$ of visible and infrared radiation and just 5-7\% of UV light [30]. Therefore, external supply of UV should be used. This can be an effective measure in reducing the hazardous effect on the environment.

From the semiconductor-photochemistry point of view, the role of a photo catalyst is to accelerate specific chemical redox reaction in the presence of irradiated semiconductors. When a photon of energy $\geq E_{g}$ of a semiconductor catalyst is used, an electron is promoted from valance band to conduction band leaving a hole behind [31]. The electron which is in the conduction band may photo catalytically reduce the organic pollutant. The conventional photocatalytic reactors are classified into many types like flat plate reactors, honeycomb monolith reactors etc. [32] which requires high intensity UV light and the high cost of these conventional reactors is another factor which denies the easy access to a platform for photo catalysis. In the industrial sector, installation cost of such photocatalytic reactors is very high and main problem associated with these reactor configurations is the issue of scale-up for commercial use [33]. A photo rector that is designed to overcome these deficiencies would be a welcome change. In this paper we introduce a new photoreactor (built in-house) with UV LED strip as the light source. This is very much cost-effective while comparing with the conventional photocatalytic reactors. Simultaneous monitoring of multiple analyses can be easily done in this system. Also, $\mathrm{Mn}_{\mathrm{X}} \mathrm{Zn}_{(1-\mathrm{X})} \mathrm{O}$ nanoparticles were synthesized using an inexpensive simple chemical co-precipitation method and its structural and optical properties have been studied. The photocatalytic reduction of $\mathrm{Cr}(\mathrm{VI})$ is studied using $\mathrm{Mn}_{\mathrm{X}} \mathrm{Zn}_{(1-\mathrm{X})} \mathrm{O}$ in a self-designed photocatalytic reactor.

\section{EXPERIMENTAL}

The materials used are zinc sulphate $\left(\mathrm{ZnSO}_{4} \cdot 7 \mathrm{H}_{2} \mathrm{O}\right)$, sodium hydroxide, cetyl trimethylammonium bromide (CTAB), manganese acetate $\left[\mathrm{Mn}\left(\mathrm{CH}_{3} \mathrm{CO}_{2}\right)_{2} \cdot 4 \mathrm{H}_{2} \mathrm{O}\right]$, oxalic acid $\left(\mathrm{C}_{2} \mathrm{H}_{2} \mathrm{O}_{4}\right), 1,5$-diphenylcarbazide (DPC), deionized water, nitric acid $\left(\mathrm{HNO}_{3}\right)$, ethanol $\left(\mathrm{C}_{2} \mathrm{H}_{5} \mathrm{OH},>99 \%\right)$, isopropyl alcohol $\left(\mathrm{C}_{3} \mathrm{H}_{8} \mathrm{O}\right)$ and Whatman No. 40 filter paper. All the chemicals were of purity $\geq 98 \%$ and were obtained from Sigma-Aldrich and the chemicals were used as received, without any further purification.

Preparation of doped and undoped $\mathrm{ZnO}$ nanoparticles: Nanoparticles of $\mathrm{Mn}_{\mathrm{x}} \mathrm{Zn}_{(1-\mathrm{x})} \mathrm{O}$, where $\mathrm{x}=0,0.05,0.10$ and 0.15 , were synthesized by chemical co-precipitation method [24,34]. To $100 \mathrm{~mL}$ solution of $11.50 \mathrm{~g}$ of $\mathrm{ZnSO}_{4} \cdot 7 \mathrm{H}_{2} \mathrm{O}$ and $0.5 \mathrm{~g}$ of CTAB, $100 \mathrm{~mL}$ solution of $\mathrm{NaOH}$ was added slowly with constant stirring using a magnetic stirrer. The stirring was continued for $2 \mathrm{~h}$ to ensure homogenous distribution. The white suspension obtained was centrifuged at $3150 \mathrm{rpm}$ for $25 \mathrm{~min}$ and washed four times with distilled water and finally washed with acetone. It was then sonicated for $25 \mathrm{~min}$ at room temperature. The precipitate was separated by filtration and calcined at $200{ }^{\circ} \mathrm{C}$ for $2 \mathrm{~h}$. Similarly, the doped samples were prepared. Here, the solution of $\mathrm{NaOH}$ is added to the solution containing both $\mathrm{ZnSO}_{4} \cdot 7 \mathrm{H}_{2} \mathrm{O}$ and $\mathrm{Mn}\left(\mathrm{CH}_{3} \mathrm{CO}_{2}\right)_{2} \cdot 4 \mathrm{H}_{2} \mathrm{O}$.

Photo reactor assembly: The assembly of self-designed homebuilt photocatalytic reactor is shown in Fig. 1 (line diagram). The photoreactor is built in-house, with a clear objective of achieving a cost-effective and easily assembled 
unit, for simultaneous monitoring of multiple analyses. The housing of the unit was made of galvanized sheet which was hammered down to a neat cabin of $2^{\prime} \times 1^{\prime} \times 2^{\prime}$ dimensions. The cabin was fit with a door of same material to enable easy handling of the sample. The inside of the cabin, including the door, was decorated with 2 " thermal insulation with proper rubber beadings to win a compact setting and minimize any heat loss that may occur during operation. The inner side of the cabin was cemented with a UV LED strip (150 V-265 V AC input, power $0.2 \mathrm{~W}$ ) in series of three tiers of equal dimensions. No strip was affixed on the roof of the cabin in order to avoid any discomfort. A magnetic stirrer was placed inside the cabin to agitate the contents of the $100 \mathrm{~mL}$ beaker, which was used as the reactor. The open beaker attracted maximum radiation and the thin walls facilitated in this action. The whole of the cabin was maintained at a static temperature of $296 \mathrm{~K}$ with the help of an insulated-ducted air-heat exchanger of $300 \mathrm{kcal} /$ $\mathrm{h}$ capacity. This profusely helped to sufficiently cool the reactor and maintain uniform temperature distribution without any gradient formation.

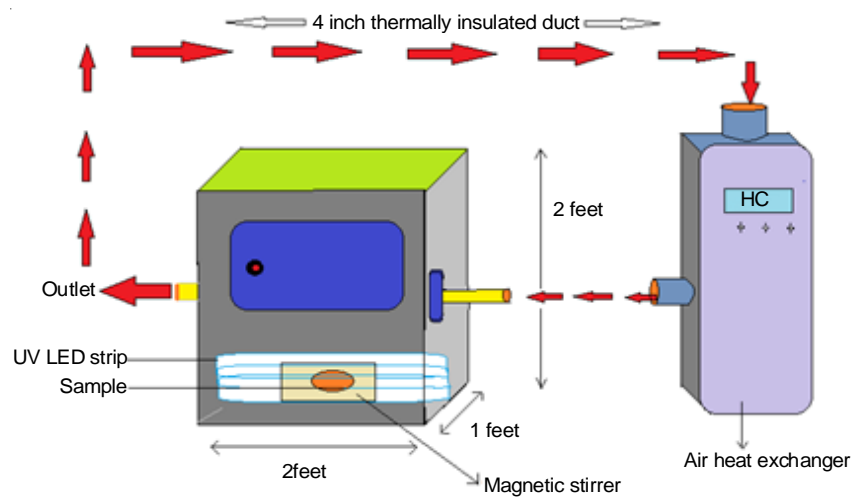

Fig. 1. Line diagram of photocatalytic reactor

Photocatalytic study: The photocatalytic activity of $\mathrm{Mn}_{\mathrm{X}} \mathrm{Zn}_{(1-\mathrm{X})} \mathrm{O}$ nanoparticles was studied following the degradation of $\mathrm{Cr}(\mathrm{VI})$ into non-toxic $\mathrm{Cr}(\mathrm{III})$. This degradation was carried out applying UV light from an external source of UV LED strip.

Characterization: The structures of doped and undoped $\mathrm{ZnO}$ were analyzed using $\mathrm{X}$-ray diffraction instrument, Philip PW1700, with $\mathrm{Cu} \mathrm{K} \alpha$ of wavelength $\lambda=1.5405 \AA$. The photo catalyzed reduction of $\mathrm{Cr}(\mathrm{VI})$ to $\mathrm{Cr}(\mathrm{III})$ was followed by UVvisible-diffuse reflectance spectra using JASCO UV-Vis NIR spectrometer (V-670).

\section{RESULTS AND DISCUSSION}

The crystal structure of the samples was characterized by X-ray diffraction technique. The XRD of prepared $\mathrm{ZnO}$ nanoparticles is as given in the Fig. 2. The peaks observed at $31.7^{\circ}, 34.25^{\circ}, 36.18^{\circ}, 47.43^{\circ}, 56.42^{\circ}, 62.6^{\circ}$ and $67.9^{\circ}$ indicate that the samples are highly crystalline. Comparing with JCPDS data 36-1451, lattice planes are identified as (100), (002), (101), (102), (110), (103) and (112), respectively, indicating hexagonal wurtzite structure of $\mathrm{ZnO}$. The broadening of the peaks gives an idea about the small particle size of the synthesized $\mathrm{ZnO}$.

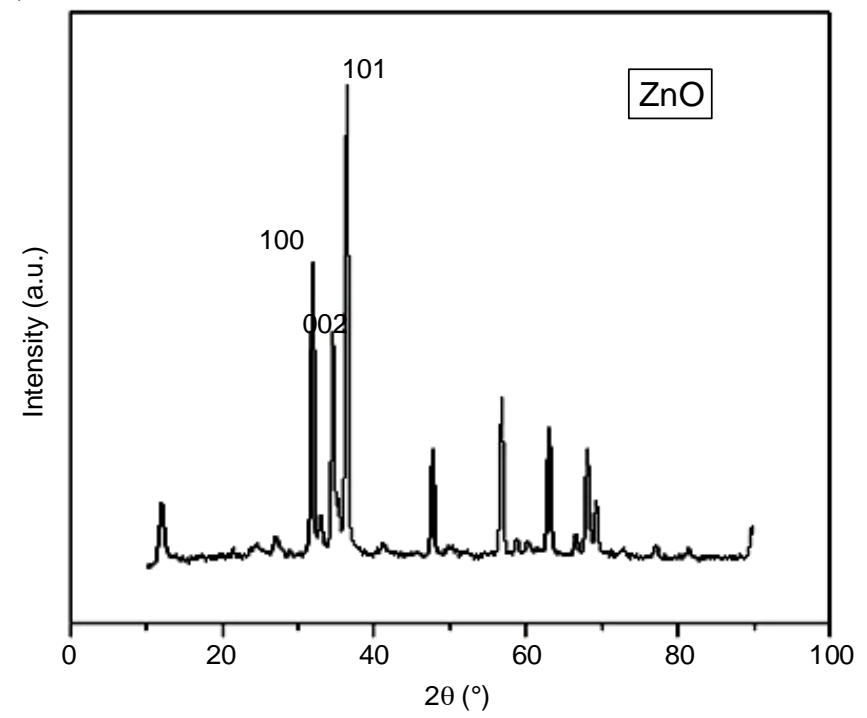

Fig. 2. XRD of as prepared $\mathrm{ZnO}$ nanoparticles

The average crystallite size (D) was calculated using the Scherer's formula [14] given below:

$$
\mathrm{D}=\frac{0.89 \lambda}{\beta \cos \theta}
$$

here, $\lambda$ and $\beta$ is the full width at half maximum (FWHM). The crystalline size calculated for the as prepared samples of $\mathrm{Mn}_{\mathrm{X}} \mathrm{Zn}_{(1-\mathrm{X})} \mathrm{O}$ is tabulated in Table- 1 .

TABLE-1

CRYSTALLINE SIZE OF THE PREPARED SAMPLES OF ZnO AND Mn DOPED ZnO

\begin{tabular}{ccccc}
\hline Sample & $\begin{array}{c}\text { Peak } \\
\text { position }\left({ }^{\circ}\right)\end{array}$ & Plane & $\beta$ & $\begin{array}{c}\text { Crystallite } \\
\text { size }(\mathrm{nm})\end{array}$ \\
\hline $\mathrm{ZnO}$ & 36.45 & & 0.4295 & 20.33 \\
$\mathrm{Mn}_{0.05} \mathrm{Zn}_{0.95} \mathrm{O}$ & 36.83 & $(101)$ & 0.4100 & 19.48 \\
$\mathrm{Mn}_{0.10} \mathrm{Zn}_{0.90} \mathrm{O}$ & 36.02 & & 0.5050 & 15.58 \\
$\mathrm{Mn}_{0.15} \mathrm{Zn}_{0.85} \mathrm{O}$ & 36.63 & & 0.7300 & 10.94 \\
\hline
\end{tabular}

From the data, it is clear that the crystallite size decreases with the increase of doping concentration since the ionic radius of $\mathrm{Mn}^{2+}(0.66 \AA)$ is smaller than that of $\mathrm{Zn}^{2+}(0.74 \AA)$ [21]. Therefore, such a variation in crystallite size is to be anticipated because of the replacement of $\mathrm{Zn}^{2+}$ with $\mathrm{Mn}^{2+}$ in the lattice. Steady increase of doping concentration of Mn progressively reduces the concentration of $\mathrm{Zn}$ in $\mathrm{Mn}_{\mathrm{x}} \mathrm{Zn}_{(1-\mathrm{X})} \mathrm{O}$. The variation in size reduction can be clarified as follows. The decrease in crystallite size as a function of Mn content can be explained by Zener pinning [34]. There are a variety of inherent defects present in $\mathrm{ZnO}$ with different ionization energies such as oxygen vacancy $\left(\mathrm{V}_{\mathrm{O}}\right)$, zinc vacancy $\left(\mathrm{V}_{\mathrm{Zn}}\right)$, oxygen interstitials $\left(\mathrm{O}_{\mathrm{i}}\right)$ and zinc interstitials $\left(\mathrm{Zn}_{\mathrm{i}}\right)$ [15]. Due to these crystal defects, the enlargement of grain boundaries becomes limited in a crystal which is called as Zener pinning effect. In the present work, after doping, the number of $\mathrm{V}_{\mathrm{O}}$ in the $\mathrm{ZnO}$ lattice may be increased. These $\mathrm{V}_{O}$ may limit the development of the crystallites on account of the Zener pinning effect. Fig. 3 shows the calculated crystallite size as a function of doping concentration in $\mathrm{Mn}_{\mathrm{X}} \mathrm{Zn}_{(1-\mathrm{X})} \mathrm{O}$, for $\mathrm{x}=0,5,10$ and $15 \%$ molar concentrations. 


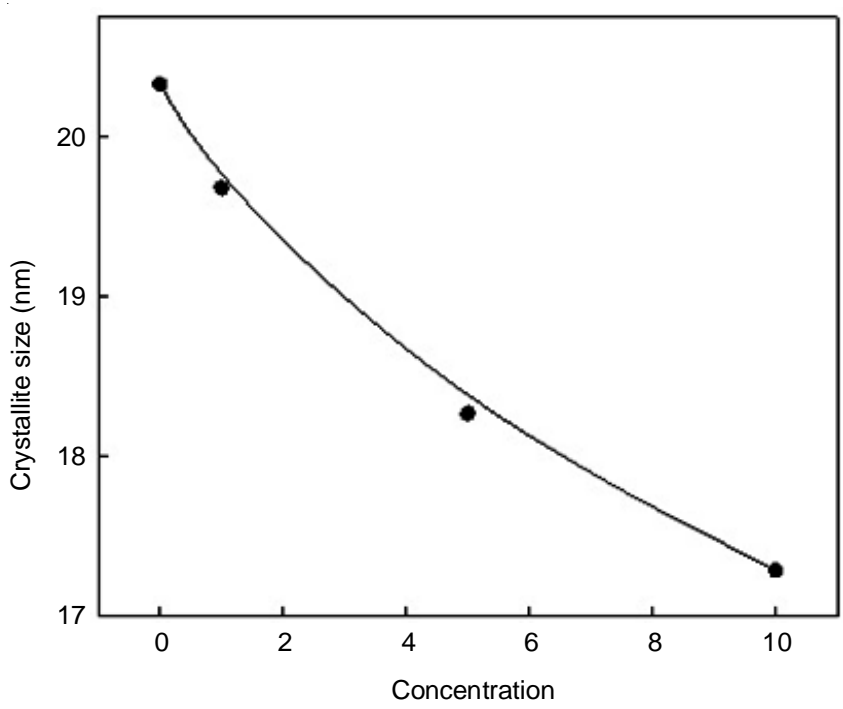

Fig. 3. Calculated crystalline size as a function of Mn doping concentration

The lattice parameters of the synthesized $\mathrm{Mn}_{\mathrm{X}} \mathrm{Zn}_{(1-\mathrm{X})} \mathrm{O}$ samples are also calculated and are tabulated in the Table- 2 . The lattice parameters are well in agreement with the standard values for 'a' and 'c' with referenc to JCPDS card no. 36-1451.

\begin{tabular}{cccc}
\multicolumn{4}{c}{ TABLE-2 } \\
CALCULATED LATTICE PARAMETERS OF \\
THE SYNTHESIZED SAMPLES \\
\cline { 2 - 3 } Sample & \multicolumn{2}{c}{ Lattice parameter $(\AA)$} & Volume $\left(\AA^{3}\right)$ \\
\cline { 2 - 3 } & $\mathrm{a}$ & $\mathrm{c}$ & 49.5801 \\
$\mathrm{ZnO}$ & 3.2729 & 5.3446 & 44.6225 \\
$\mathrm{Mn}_{0.05} \mathrm{Zn}_{0.95} \mathrm{O}$ & 3.1640 & 5.1616 & 43.9968 \\
$\mathrm{Mn}_{0.10} \mathrm{Zn}_{0.90} \mathrm{O}$ & 3.1525 & 5.1232 & 44.1448 \\
$\mathrm{Mn}_{0.15} \mathrm{Zn}_{0.85} \mathrm{O}$ & 3.1411 & 5.1716 & \\
\hline
\end{tabular}

UV-visible optical characterization: The room temperature optical measurements were performed using a UVvisible-near infrared spectrophotometer. Absorbance spectra of $\mathrm{Mn}_{\mathrm{X}} \mathrm{Zn}_{(1-\mathrm{X})} \mathrm{O}$ nanoparticles are shown in the Fig. 4 and the deviation of the absorbed wavelength with increase in doping

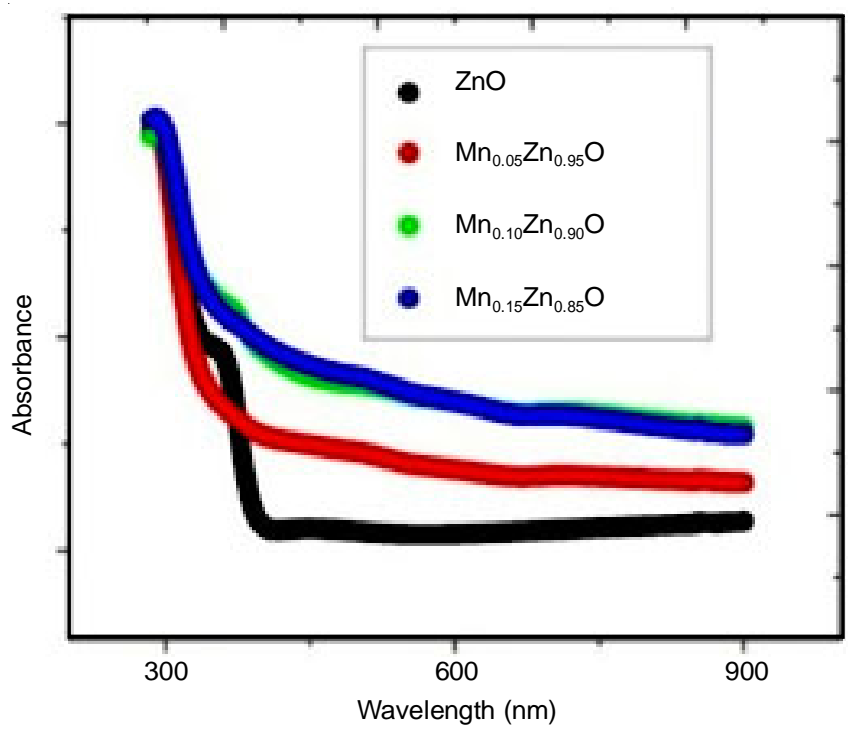

Fig. 4. Absorbance spectra of $\mathrm{ZnO}$ and $\mathrm{Mn}$ doped $\mathrm{ZnO}$ samples concentration indicates the variation of $\mathrm{E}_{\mathrm{g}}$. In the absorption spectra, a blue-shift (wavelength-decrease) can be seen along with increase in doping concentration. The blue-shift in the $\mathrm{E}_{\mathrm{g}}$ is due to the substitution of $\mathrm{Zn}^{2+}$ ions in the $\mathrm{ZnO}$ lattice by $\mathrm{Mn}^{2+}$ ions. In addition to this, the shift in the band gap energy with increase in the doping concentration of Mn can be attributed to the energy difference among the top of the valence band and the vacant energy states in the conduction band [16,35].

The $\mathrm{E}_{\mathrm{g}}$ for the $\mathrm{ZnO}$ and $\mathrm{Mn}_{\mathrm{X}} \mathrm{Zn}_{(1-\mathrm{X})} \mathrm{O}$ was calculated using the relation $(\alpha \mathrm{h} v)=\sqrt{\left(\mathrm{h} v-\mathrm{E}_{\mathrm{g}}\right)}$, where $\alpha$ is the absorbance and $h v$ is the photon energy. To estimate the $\mathrm{E}_{\mathrm{g}},(\alpha \mathrm{h} v)$ versus hv plot was constructed [Fig. 5(a-d)]. The value of $\mathrm{E}_{\mathrm{g}}$ was evaluated taking the intercept of the extrapolation to zero absorption with axis, i.e. tends to zero. The approximate $\mathrm{E}_{\mathrm{g}}$ value of the $\mathrm{ZnO}$ is $3.25 \mathrm{eV}$ which is slightly lower compared to standard value of $3.37 \mathrm{eV}$ [15].

The calculated values of $\mathrm{E}_{\mathrm{g}}$ are presented in Table-3. The $\mathrm{E}_{\mathrm{g}}$ of the samples increased linearly from 3.25 to $3.68 \mathrm{eV}$. The increase in $\mathrm{E}_{\mathrm{g}}$ with the increase in doping concentration might be ascribed to the alteration of electronic arrangement on doping of $\mathrm{Mn}$ ions into the $\mathrm{ZnO}$ lattice.

TABLE-3

OPTICAL BAND GAP $\left(\mathrm{E}_{\mathrm{g}}\right)$ OF THE $\mathrm{Mn}_{\mathrm{x}} \mathrm{Zn}_{(1-\mathrm{x})} \mathrm{O}$ SAMPLES

\begin{tabular}{cc}
\hline Sample & Energy gap $(\mathrm{eV})$ \\
\hline $\mathrm{ZnO}$ & $\sim 3.25$ \\
$\mathrm{Mn}_{0.05} \mathrm{Zn}_{0.95} \mathrm{O}$ & $\sim 3.60$ \\
$\mathrm{Mn}_{0.10} \mathrm{Zn}_{0.90} \mathrm{O}$ & $\sim 3.65$ \\
$\mathrm{Mn}_{0.15} \mathrm{Zn}_{0.85} \mathrm{O}$ & $\sim 3.68$ \\
\hline
\end{tabular}

There are many calculations and measurements showing that the band gap of pure $\mathrm{ZnO}$ depends on the technique of preparation which affects both the oxygen stoichiometry and the grain size. However, it has recently been reported that the $\mathrm{E}_{\mathrm{g}}$ can vary between $3.13 \mathrm{eV}$ and $4.06 \mathrm{eV}$ for films deposited by metal-organic chemical vapour deposition (MOCVD) [36]. Fukumura et al. [37] and Jung et al. [38] examined the blueshift in $\mathrm{E}_{\mathrm{g}}$ with increase in concentration of $\mathrm{Mn}$ in thin films of $\mathrm{Mn} @ \mathrm{ZnO}$. The conclusion of Fukumura et al. [37] reveals that an initial decrease of $\mathrm{E}_{\mathrm{g}}$ for small concentrations of $\mathrm{Mn}$ $(<3 \mathrm{~mol} \%)$ followed by an increase of $\mathrm{E}_{\mathrm{g}}$ for higher doping concentrations of $\mathrm{Mn}(>3 \mathrm{~mol} \%)$ in the mixed samples $\mathrm{MnZnO}$ so long as it remains in the wurtzite structure. This type of discrepancy of non-linear variation of band gap is more prominent in the study of Mn-doped $\mathrm{ZnO}$ nanocrystals reported by Viswanatha et al. [16]. This phenomenon is predicted on the basis of virtual crystal approximation (VCA) because of the higher band gap of $\mathrm{MnO}$, nearly $4.2 \mathrm{eV}[26,39]$. The $\mathrm{E}_{\mathrm{g}}$ of $\mathrm{Mn}_{\mathrm{X}} \mathrm{Zn}_{(1-\mathrm{X})} \mathrm{O}$ samples prepared during the course of this investigation is increased from $3.25 \mathrm{eV}$, when $\mathrm{x}=0$, to $3.60,3.65$ and $3.68 \mathrm{eV}$, when $\mathrm{x}=0.05,0.10$ and 0.15 , respectively, indicating that the $\mathrm{Mn}$ is incorporated in $\mathrm{ZnO}$ as expected.

\section{Photo catalysis}

Photocatalytic degradation of $\mathbf{C r}(\mathrm{VI})$ : The reduction of $\mathrm{Cr}(\mathrm{VI})$ to $\mathrm{Cr}$ (III) was studied to evaluate the photocatalytic activity of $\mathrm{Mn}_{\mathrm{X}} \mathrm{Zn}_{(1-\mathrm{X})} \mathrm{O}$ samples. The optical absorption of 

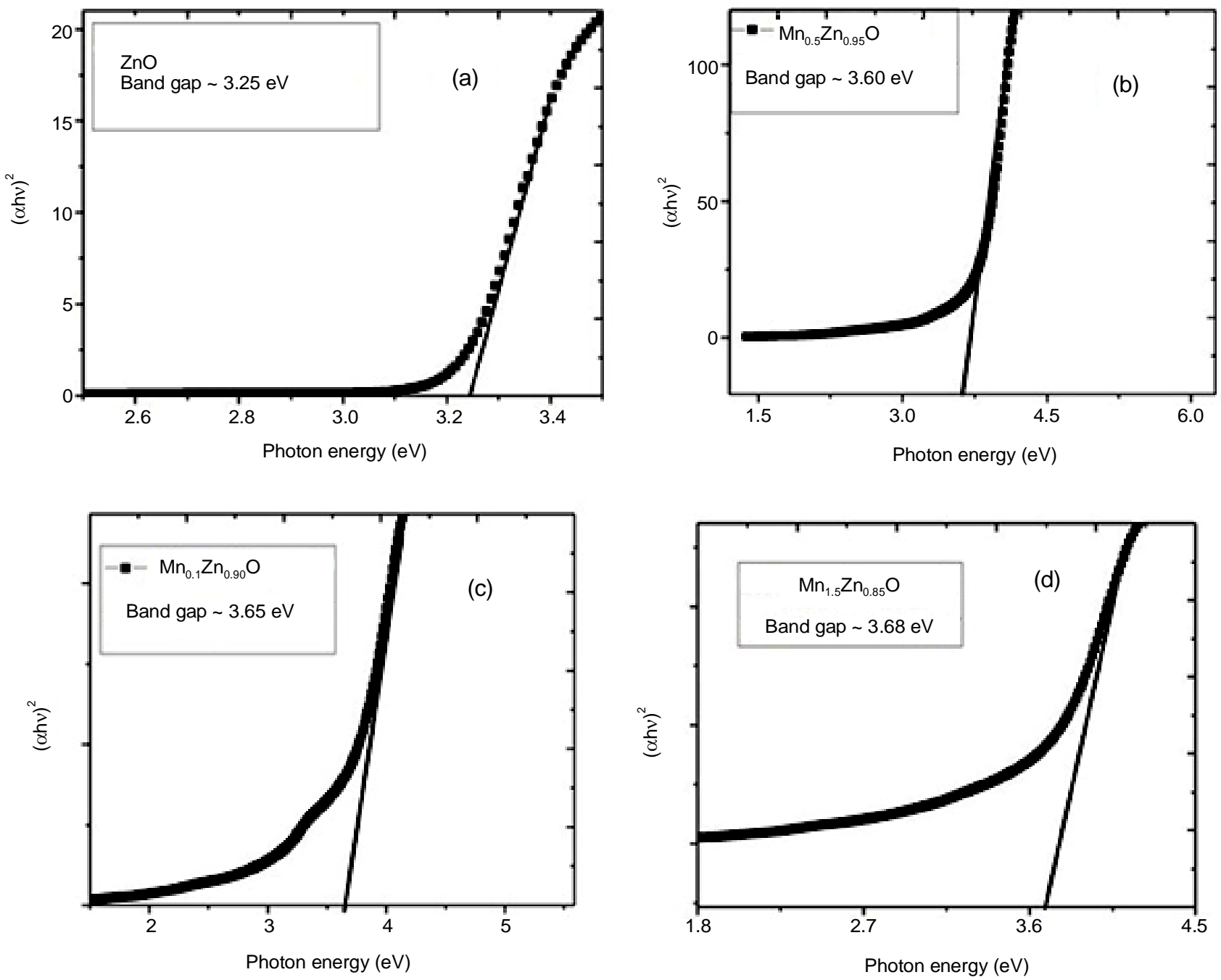

Fig. 5. Optical absorbance spectra of (a) $\mathrm{ZnO}$, (b) $\mathrm{Mn}_{0.05} \mathrm{Zn}_{0.95} \mathrm{O}$, (c)

$\mathrm{Cr}(\mathrm{VI})$ solution was measured using UV/visible spectrophotometer to understand the photocatalytic degradation of $\mathrm{Cr}(\mathrm{VI})$. The degradation of $\mathrm{Cr}(\mathrm{VI})$ was investigated with UV light irradiation of both undoped and doped samples under the same ambient conditions. Upon irradiation with UV light, the electrons jump from valence band (VB) to conduction band (CB) creating holes in valence band. The reduction potential for $\mathrm{Cr}(\mathrm{VI})$ to $\mathrm{Cr}(\mathrm{III})$ with respect to standard hydrogen electrode is $1.33 \mathrm{~V}$ [20]. If the chosen catalytic material's conduction band edge is above $1.33 \mathrm{~V}$, the electron, which is in the conduction band, may photocatalytically reduce $\mathrm{Cr}(\mathrm{VI})$ to $\mathrm{Cr}$ (III) [20].

Photocatalytic activity of $\mathbf{M n}_{\mathbf{X}} \mathbf{Z} \mathbf{n}_{(1-x)} \mathbf{O}$ : In the present work, the photocatalytic activity of pure $\mathrm{ZnO}$ and $\mathrm{Mn}$ doped $\mathrm{ZnO}$ was studied for the degradation of $\mathrm{Cr}(\mathrm{VI})$ to $\mathrm{Cr}(\mathrm{III})$. The reaction pathway for the reduction of $\mathrm{Cr}(\mathrm{VI})$ in the presence of $\mathrm{Mn}_{\mathrm{X}} \mathrm{Zn}_{(1-\mathrm{X})} \mathrm{O}$ photocatalyst follows. To carry out the experiment, each time $100 \mathrm{~mL}$ of $50 \mathrm{ppm} \mathrm{Cr}(\mathrm{VI})$ solution was taken with $10 \mathrm{mM}$ oxalic acid as the hole scavenger and into it $30 \mathrm{mg}$ of the prepared sample was added. This was kept for UV treatment in dark. This sample was studied in different time interval to get a clear idea about the reduction of the toxic $\mathrm{Cr}$ (VI) to $\mathrm{Cr}$ (III). Diphenyl carbazide (DPC) was used as the indicator. The residual Cr(VI) concentration was determined by UV-visible spectrophoto- meter at $540 \mathrm{~nm}$ after complexion with DPC. Figs. 6-8 represent the depicts of the normalized concentrations of $\mathrm{Cr}$ solution as a function of UV irradiation time over the as-prepared $\mathrm{Mn}_{\mathrm{X}} \mathrm{Zn}_{(1-\mathrm{X})} \mathrm{O}$

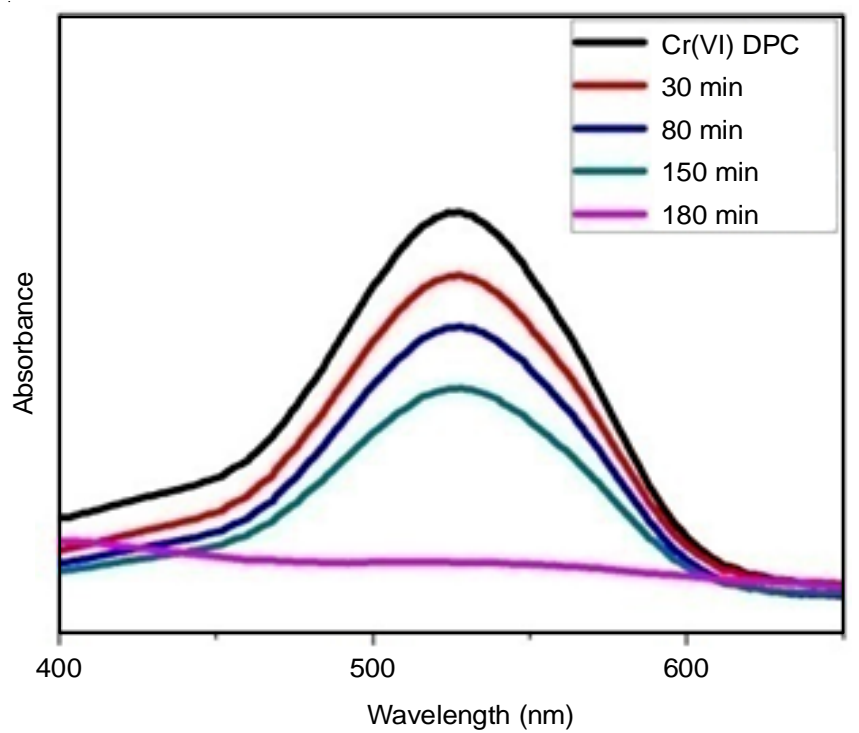

Fig. 6. Reduction of $\mathrm{Cr}(\mathrm{VI})$ with prepared $\mathrm{ZnO}$ 


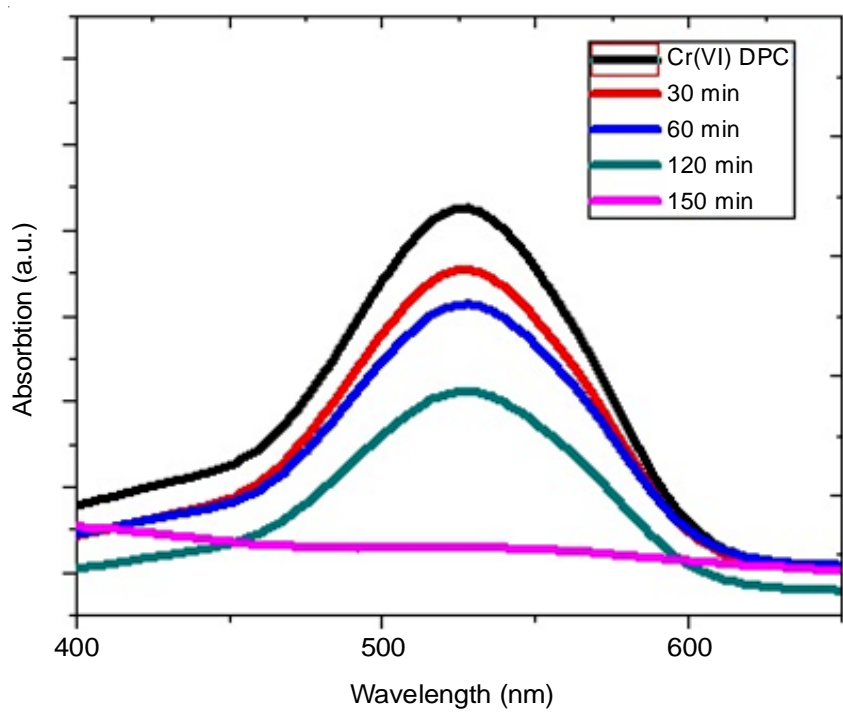

Fig. 7. Reduction of $\mathrm{Cr}(\mathrm{VI})$ with $5 \%$ of $\mathrm{Mn}$ doped $\mathrm{ZnO}$

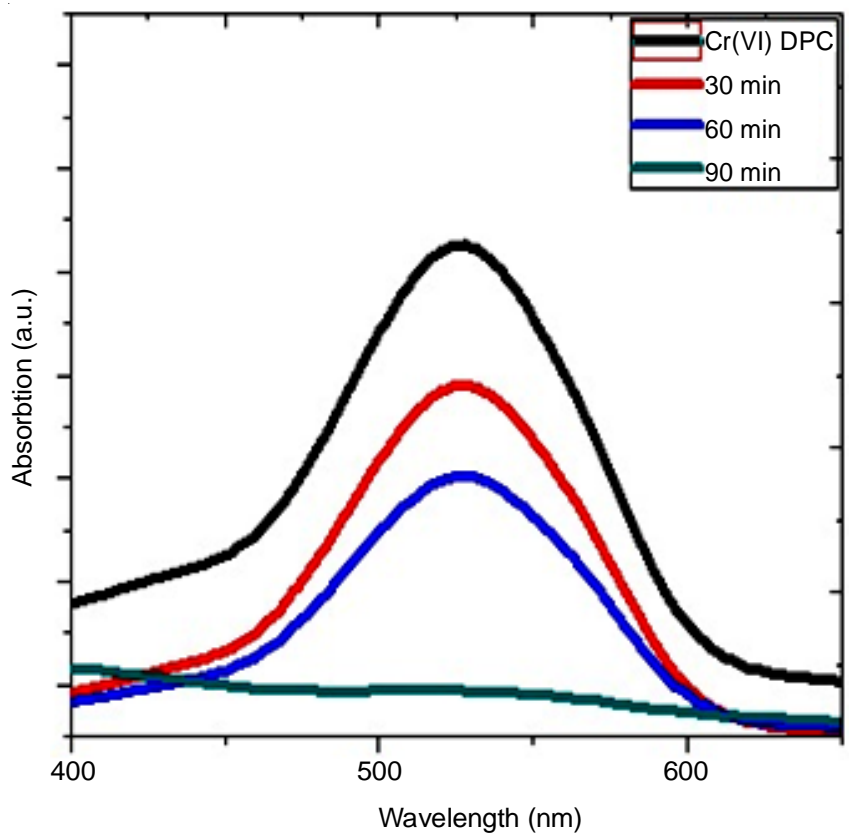

Fig. 8. Reduction of $\mathrm{Cr}(\mathrm{VI})$ with $10 \%$ of $\mathrm{Mn}$ doped $\mathrm{ZnO}$

nanoparticles. In comparison with slow degradation process of $\mathrm{Cr}$, under $\mathrm{UV}$ irradiation, with undoped $\mathrm{ZnO}$ nanoparticles, the $\mathrm{Mn}$ doped $\mathrm{ZnO}$ nanoparticles noticeably accelerated the reduction of $\mathrm{Cr}$ and the efficiency increases with increase of Mn concentration.

The result from the photocatalytic study shows that pure $\mathrm{ZnO}$ as the catalyst took $180 \mathrm{~min}$ for the reduction of $\mathrm{Cr}(\mathrm{III})$, where the intensity of the peak is reduced and the absorbance reached almost zero. When $\mathrm{Mn}_{0.05} \mathrm{Zn}_{0.95} \mathrm{O}$ was used as the photocatalytic agent for reducing $\mathrm{Cr}(\mathrm{VI})$, the time taken for the reduction into $\mathrm{Cr}(\mathrm{III})$ is less than what is required with pure $\mathrm{ZnO}$. The reaction gets completed roughly by $150 \mathrm{~min}$, where the intensity of the absorbance peak almost comes to zero. On the other hand, when $\mathrm{Mn}_{0.10} \mathrm{Zn}_{0.90} \mathrm{O}$ used as the photocatalytic agent, the time required for the complete reduction of $\mathrm{Cr}(\mathrm{VI})$ to $\mathrm{Cr}(\mathrm{III})$ is about $90 \mathrm{~min}$. With $\mathrm{Mn}_{0.15} \mathrm{Zn}_{0.85} \mathrm{O}$, the intensity of the peak, corresponding to the complex of $\mathrm{Cr}(\mathrm{VI})$ with 1,5-diphenyl carbazide, completely get reduced within 60 min. The inference made from this observation is that the time taken for photocatalytic reduction decreases with increase in doping concentration, which was again confirmed by observing the photocatalytic activity under constant time for different dopant concentration.

Effect of doping on photo catalysis: To study the dependence of photo catalysis on doping concentration, a plot has been made (Fig. 9) where we observe the photocatalytic activity under constant time (30 min) for different Mn concentration. As dopant concentration increases, more vacancies are produced in the crystal lattice [30]. These vacancies can increase the number of electrons in conduction band by effectively separating hole-electron pairs with the help of hole scavenger like oxalic acid. Increase in doping concentration can generate more and more free electrons for conduction. These electrons, after getting excited from the valence band to the conduction band, make the reduction faster. Thus, we can account for the reduction in time with increasing doping concentration.

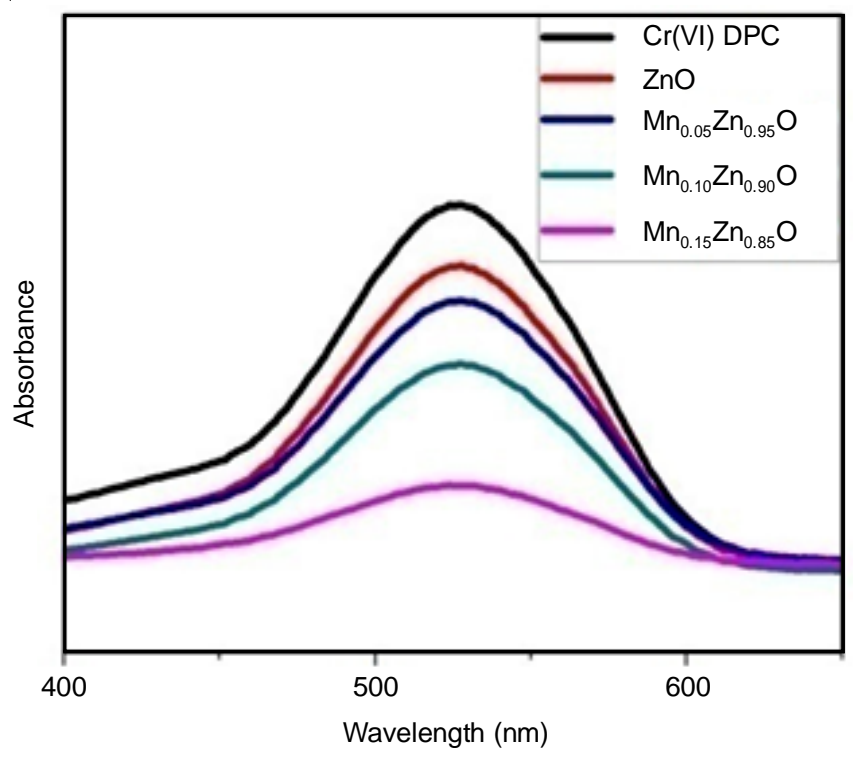

Fig. 9. Reduction of $\mathrm{Cr}(\mathrm{VI})$ in $30 \mathrm{~min}$ for various Mn concentration

Also, as and when the doping concentration is increased, more and more complimentary electrons will be created for conduction. These electrons, after getting excited from valence band to conduction band, undergo secondary reactions with the free radicals $\left({ }^{\circ} \mathrm{OH}\right)$, which makes the reduction faster $[13,40]$.

\section{Conclusion}

The work presented here has been focused on the studies on structural, optical and photocatalytic properties of $\mathrm{ZnO}$ and $\mathrm{Mn}$ doped $\mathrm{ZnO}$ nanoparticles, synthesized by chemical coprecipitation method. We noticed the $\mathrm{E}_{\mathrm{g}}$ of the $\mathrm{ZnO}$ nanoparticles varies with $\mathrm{Mn}$ doping. Also we observed that photocatalytic reduction time reduces with increasing doping concentration. The $\mathrm{Mn}_{\mathrm{x}} \mathrm{Zn}_{(1-\mathrm{x})} \mathrm{O}$ nanoparticles has been observed as an excellent photo catalyst and it showed promising result for the degradation of $\mathrm{Cr}(\mathrm{VI})$. 


\section{ACKNOWLEDGEMENTS}

One of the authors (KMS) gratefully acknowledge the financial, academic and technical support from Amrita Vishwa Vidyapeetham through AMRITA/IFRP-26/2015/16/08. The authors also thank all members of Department of Sciences, Amrita School of Engineering, Amrita Vishwa Vidyapeetham, Coimbatore, India.

\section{CONFLICT OF INTEREST}

The authors declare that there is no conflict of interests regarding the publication of this article.

\section{REFERENCES}

1. D.S. Bhatkhande, V.G. Pangarkar and A.A. Beenackers, J. Chem. Technol. Biotechnol., 77, 102 (2002);

https://doi.org/10.1002/jctb.532.

2. W. Giurlani, G. Zangari, F. Gambinossi, M. Passaponti, E. Salvietti, F. Di Benedetto, S. Caporali and M. Innocenti, Coatings, 8, 260 (2018); https://doi.org/10.3390/coatings8080260.

3. A. Mills, A. Belghazi and D. Rodman, Water Res., 30, 1973 (1996); https://doi.org/10.1016/0043-1354(96)00012-7.

4. J. Gimenez, M. Aguado and S. Cervera-March, J. Mol. Catal. Chem., 105, 67 (1996); https://doi.org/10.1016/1381-1169(95)00148-4.

5. Y. Xing, X. Chen and D. Wang, Environ. Sci. Technol., 41, 1439 (2007); https://doi.org/10.1021/es0614991.

6. N. Daneshvar, D. Salari and S. Aber, J. Hazard. Mater, 94, 49 (2002); https://doi.org/10.1016/S0304-3894(02)00054-7.

7. T. Ölmez, J. Hazard. Mater., 162, 1371 (2009); https://doi.org/10.1016/j.jhazmat.2008.06.017.

8. X. Liu, L. Pan, Q. Zhao, T. Lv, G. Zhu, T. Chen, T. Lu, Z. Sun and C. Sun, Chem. Eng. J., 183, 238 (2012); https://doi.org/10.1016/j.cej.2011.12.068.

9. J.C. Fan, K.M. Sreekanth, Z. Xie, S.L. Chang and K.V. Rao, Prog. Mater. Sci., 58, 874 (2013); https://doi.org/10.1016/j.pmatsci.2013.03.002.

10. K.K. Kim, N. Koguchi, Y.W. Ok, T.-Y. Seong and S.-J. Park, Appl. Phys. Lett., 84, 3810 (2004); https://doi.org/10.1063/1.1741030.

11. C. Jagadish and S.J. Pearton, Zinc Oxide Bulk, Thin Films and Nanostructures: Processing, Properties and Applications, Elsevier (2011).

12. J.X. Wang, X.W. Sun, A. Wei, Y. Lei, X.P. Cai, C.M. Li and Z.L. Dong, Appl. Phys. Lett., 88, 233106 (2006); https://doi.org/10.1063/1.2210078.

13. M. Behnajady, N. Modirshahla and R. Hamzavi, J. Hazard. Mater., 133, 226 (2006); https://doi.org/10.1016/j.jhazmat.2005.10.022.

14. K.S. Mahavdeva, Ph. D. Thesis, Department of Material Science and Engineering, KTH-The Royal Institute of Technology, Stockhom, Sweden (2013).

15. T.A. Arun, D.K. Chacko, A.A. Madhavan, T.G. Deepak, G.S. Anjusree, T. Sara, S. Ramakrishna, S.V. Nair and A. Nair, RSC Adv., 4, 1421 (2014); https://doi.org/10.1039/C3RA45021J.

16. R. Viswanatha, S. Sapra, S. Sen Gupta, B. Satpati, P.V. Satyam, B.N. Dev and D.D. Sarma, J. Phys. Chem. B, 108, 6303 (2004); https://doi.org/10.1021/jp049960o.
17. G.C.C. Yang and S.-W. Chan, J. Nanopart. Res., 11, 221 (2009); https://doi.org/10.1007/s11051-008-9423-y.

18. S. Chakrabarti, B. Chaudhuri, S. Bhattacharjee, A.K. Ray and B.K. Dutta, Chem. Eng. J., 153, 86 (2009); https://doi.org/10.1016/j.cej.2009.06.021.

19. T. Jafari, E. Moharreri, A.S. Amin, R. Miao, W. Song and S.L. Suib, Molecules, 21, 900 (2016); https://doi.org/10.3390/molecules21070900.

20. P.D. Tran, L. Xi, S.K. Batabyal, L.H. Wong, J. Barber and J.S. Chye Loo, Phys. Chem. Chem. Phys., 14, 11596 (2012); https://doi.org/10.1039/c2cp41450c.

21. H. Morkoç and Ü. Özgür, Zinc Oxide: Fundamentals, Materials and Device Technology, Wiley-VCH Verlag GmbH \& Co. KGaA, p. 323 (2009).

22. S.K. Kansal and Prerna, Energy Environm. Focus, 2, 203 (2013); https://doi.org/10.1166/eef.2013.1054.

23. Q. Xu, S. Zhou and H. Schmidt, J. Alloys Compd., 487, 665 (2009); https://doi.org/10.1016/j.jallcom.2009.08.033.

24. R.S. Yadav, A.C. Pandey and S.S. Sanjaya, Chalcogenide Lett., 6, 233 (2009).

25. N. Riahi-Noori, R. Sarraf-Mamoory, P. Alizadeh and A. Mehdikhani, J. Ceram. Process. Res., 9, 246 (2008).

26. S. Senthilkumaar, K. Rajendran, S. Banerjee, T.K. Chini and V. Sengodan, Mater. Sci. Semicond. Process., 11, 6 (2008); https://doi.org/10.1016/j.mssp.2008.04.005.

27. S. Ekambaram, Y. Iikubo and A. Kudo, J. Alloys Compd., 433, 237 (2007); https://doi.org/10.1016/j.jallcom.2006.06.045.

28. R. Ullah and J. Dutta, J. Hazard. Mater, 156, 194 (2008); https://doi.org/10.1016/j.jhazmat.2007.12.033

29. J.M. Herrmann, Catal. Today, 53, 115 (1999); https://doi.org/10.1016/S0920-5861(99)00107-8.

30. T. Bak, J. Nowotny, M. Rekas and C.C. Sorrell, Int. J. Hydrogen Energy, 27, 991 (2002); https://doi.org/10.1016/S0360-3199(02)00022-8

31. A.B. Djurisic, Y.H. Leung and A.M. Ching Ng, Mater. Horiz., 1, 400 (2014); https://doi.org/10.1039/c4mh00031e.

32. M.S. Birnie, S. Riffat and M. Gillott, Int. J. Low-Carbon Technol., 1, 47 (2006); https://doi.org/10.1093/ijlct/1.1.47.

33. P.S. Mukherjee and A.K. Ray, Chem. Eng. Technol., 22, 253 (1999); https://doi.org/10.1002/(SICI)1521-4125(199903)22:3<253::AIDCEAT253>3.0.CO;2-X.

34. R.W. Kelsall, I.W. Hamley and M. Geoghegan, Nanoscale Science and Technology, John Wiley \& Sons, West Sussex (2005).

35. T.L. Tan, C.W. Lai and S.B. Abd Hamid, J. Nanomater., ID 371720 (2014); https://doi.org/10.1155/2014/371720.

36. S.T. Tan, B.J. Chen, X.W. Sun, W.J. Fan, H.S. Kwok, X.H. Zhang and S.J. Chua, J. Appl. Phys., 98, 013505 (2005); https://doi.org/10.1063/1.1940137.

37. T. Fukumura, Z. Jin, A. Ohtomo, H. Koinuma and M. Kawasaki, Appl. Phys. Lett., 75, 3366 (1999); https://doi.org/10.1063/1.125353.

38. S.W. Jung, S.-J. An, G.-C. Yi, C.U. Jung, S.-I. Lee and S. Cho, Appl. Phys. Lett., 80, 4561 (2002); https://doi.org/10.1063/1.1487927.

39. S.V. Bhat and F.L. Deepak, Solid State Commun., 135, 345 (2005); https://doi.org/10.1016/j.ssc.2005.05.051.

40. F. Djouider and A. Hussain, J. Hazard. Mater., 276, 19 (2014); https://doi.org/10.1016/j.jhazmat.2014.05.004. 